K. PIETRZAK*\# A. GŁADKI*, K. FRYDMAN*, D. WÓJCIK-GRZYBEK*,

A. STROJNY-NĘDZA*, T. WEJRZANOWSKI**

\title{
COPPER-CARBON NANOFORMS COMPOSITES - PROCESSING, MICROSTRUCTURE AND THERMAL PROPERTIES
}

\begin{abstract}
The main current of publication is focused around the issues and problems associated with the formation of composite materials with $\mathrm{Cu}$ matrix and reinforcing phases in the various carbon nanoforms. The core of the research has been focused on thermal conductivity of these composites types. This parameter globally reflects the state of the structure, quality of raw materials and the technology used during the formation of composite materials. Vanishingly low affinity of copper for carbon, multilayered forms of graphene, the existence of critical values of graphene volume in the composite are not conducive to the classic procedures of composites designing. As a result, the expected, significant increase in thermal conductivity of composites is not greater than for pure copper matrix. Present paper especially includes: (i) data of obtaining procedure of copper/graphene mixtures, (ii) data of sintering process, (iii) the results of structure investigations and of thermal properties. Structural analysis revealed the homogenous distribution of graphene in copper matrix, the thermal analysis indicate the existence of carbon phase critical concentration, where improvement of thermal diffusivity to pure copper can occur.
\end{abstract}

Keywords: metal matrix composite, sintering, copper, graphene, thermal diffusivity

\section{Introduction}

It took a decade from the time when the concept of graphene permanently occurred in materials science [1-4]. It is a time long enough to summarize the properties of graphene forms used as a reinforcing phase in composites, especially copper matrix. The properties of graphene and carbon nano tubes (CNT) are often compared with the corresponding copper, particularly thermal and electrical conductivity. The measured value of thermal conductivity for graphene and CNT in room temperature [5-6] is about $5000 \mathrm{~W} / \mathrm{mK}$ and for copper $400 \mathrm{~W} / \mathrm{mK}$. Electrical conductivity is similar for both materials, slightly higher for graphene $0.96 \times 10^{6} 1 / \Omega \mathrm{cm}$ and for the copper $0.60 \times 10^{6} 1 / \Omega \mathrm{cm}[7]$. Large differences in the thermal conductivity of copper and graphene encourage to production of a composite material with a copper matrix, while the reinforcing phase of graphene significantly improves the thermal properties of the material. Simple, theoretical estimation [8] shows that 1vol.\% graphene should improve the thermal conductivity of the composites of $10 \%$ relative to pure copper. Measurements of thermal conductivity in thin layers of composite $\mathrm{Cu} / \mathrm{G}$ confirm this hypothesis. Experimental data for the powder composite $\mathrm{Cu} / \mathrm{G}(\mathrm{CNT})$ are significantly different from the theoretical predictions [9-10]. In the range studied and documented of graphene (0.1-10.0vol.\%) in the matrix of copper, the decrease in thermal conductivity copper-graphene composites with increasing volume fraction of graphene was noted. This fact is explained by the presence of various structural graphene forms defects [11], their radical impact on reducing the thermal conductivity of composites. The special role of $\mathrm{Cu}-\mathrm{C}$ interface - due to the lack of chemical affinity between the copper and carbon - is often emphasized, because it makes difficult the heat flux in the composite [12]. In summary, thermal conductivity of copper matrix composites reinforced by graphene forms is dependent on: the quality of the carbon forms, homogeneity of the mixture components, quantitative volumetric relationship copper to graphene and selection of the sintering method. The studies presented below have focused on obtaining homogeneous phases in the form of multi-walled nanotubes (MWNTs), flakes of graphene powder and quality graphene structures and their influence on heat conductivity of the composite were verified by examining composite $\mathrm{Cu} / \mathrm{G}(\mathrm{CVD})$. The choice of sintering composite powders method, under the condition minimum porosity of the material, was made in second step. Finally, from set of thermal conductivity results the best were compared to the worst and root cause analysis has been carried out. In this sequence, the experiment is described below.

* INSTITUTE OF ELECTRONIC MATERIALS TECHNOLOGY, 133 WOLCZYNSKA STR., 01-919 WARSAW, POLAND

** FACULTY OF MATERIALS SCIENCE AND ENGINEERING, WARSAW UNIVERSITY OF TECHNOLOGY, WOLOSKA 141 STR., WARSAW, POLAND

\# Corresponding author: katarzyna.pietrzak@itme.edu.pl 


\section{Experimental procedure}

The presented results concern three groups of $\mathrm{Cu} /$ carbon nanoforms composites reinforced by: (i) multi-walled nanotubes (MWNT) from Aldrich company, (ii) graphene nanopowder (GNP) of Skyspring Nanomaterials Inc. and (iii) CVD graphene made in ITME, as a matrix dendrite copper powder $(10 \mu \mathrm{m}$ particle size) from Aldrich was used (Fig. 1).

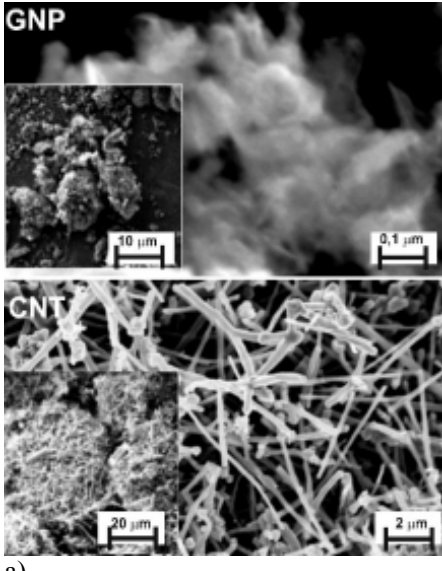

a)

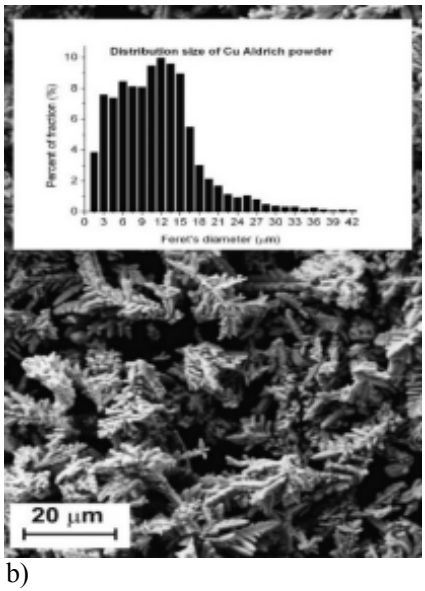

Fig. 1. SEM images of: a) globular structure of GNP and CNT(MWNT) materials and b) copper powder and its size distribution

Measured by BET specific surface area $\mathrm{S}_{\mathrm{V}}$ of copper powder was equal $\mathrm{S}_{\mathrm{v}}=0.62 \mathrm{~m}^{2} / \mathrm{g}$. XRD no identifying any other crystalline form than copper. In contrast, thermal analysis TGA revealed the existence of copper oxide $\mathrm{CuO}$. CNT had a XRD diffraction pattern characteristic for graphene oxide. Raman spectrum of MWNTs was typical for graphene oxides. On the other hand, the nature of the Raman spectrum of graphene nanopowder enabled to distinguish the following features of this material: carbon plane strongly defected - high intensity modes $\mathrm{D}$ and $\mathrm{D}^{\prime}$; activation module $\mathrm{D}^{\prime \prime}$ is related to the concentration of carbon $\mathrm{sp}^{3}$ hybridization and proportionate to the defects in the carbon planes; single, extended bandwidth 2D indicates a material having a thickness of 4-6 layers other than the Bernal arrangement. The graphene layers of copper powder were made by CVD Aixtron VP508 horizontal hot wall CVD reactor. Raman spectrum indicates high-quality graphene material. In Fig. 2 the structural changes of the original powder $\mathrm{Cu}$ and after the $\mathrm{CVD}$ process are showed. The high temperature of the CVD process makes that the morphology of the powder is completely changed. Dramatically decrease the specific surface area and the graphene flakes covered the copper grains.

To get effect of uniform in size, and the separated GNP and MWNT structures, sonication and spin processes were used. $\mathrm{Cu} / \mathrm{X}$ vol.\% GNP composite powders were prepared by mixing the directly dispersed GNP with copper powder. The mixtures MWNT in aqueous Triton X-100 were filtered through a layer of powder of a specified mass. At the level of content below 1vol.\% MWNTs/Cu single and well separated CNT were observed (Fig. 3a). Above this value were found numerous clusters of MWNT.

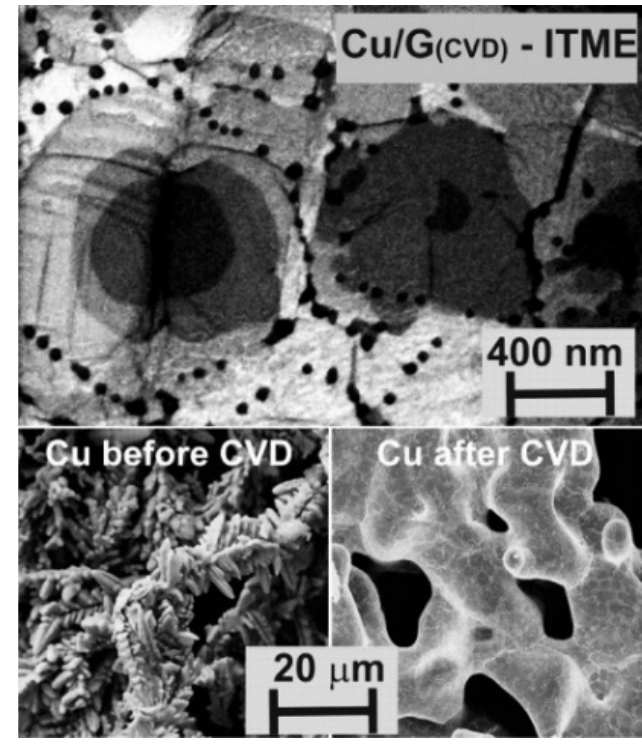

Fig. 2. SEM images of the $\mathrm{Cu}$ powder before and CVD process after

The number of MWNT in clusters and the same number of clusters increased in proportion to the concentration of CNT in the matrix of copper. Similarly, the increase in concentration of GNP in the matrix $\mathrm{Cu}$, especially above 3 vol. $\% \mathrm{GNP} / \mathrm{Cu}$, becomes visible as agglomerates of this carbon form (Fig. 3b). They decorate practically the entire surface of the $\mathrm{Cu}$ matrix, concentrating in the niches of the extensive surface copper powder.

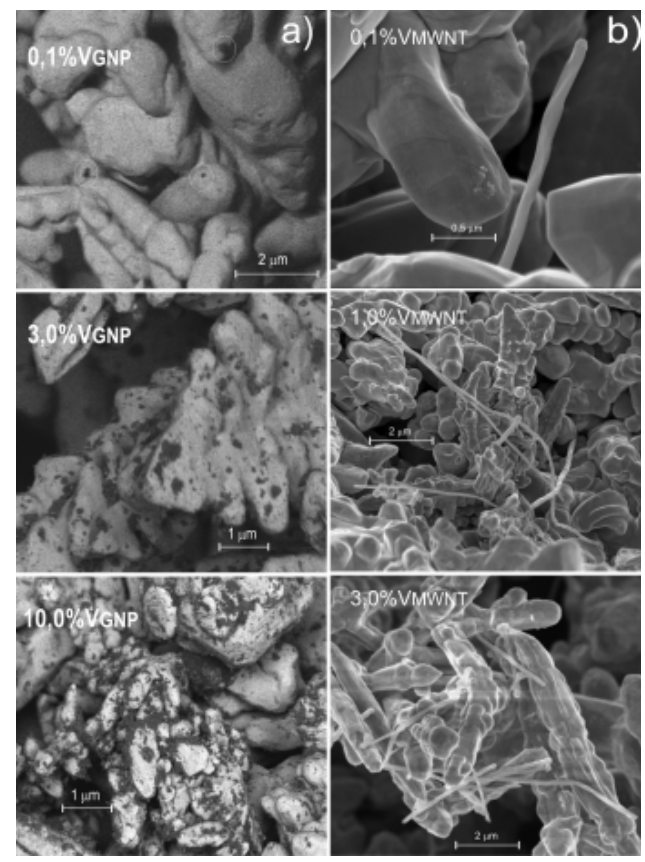

Fig. 3. The surfaces of the copper powder with a varying volumes of MWNT concentration (a) and the surfaces of the copper powder coated GNP with a varying volume concentration (b).

In the initial phase of the study, three different methods of sintering were tested. In the classical method - pressing and sintering - pressure of the material formed was $15 \mathrm{MPa}$. Molders were sintered in an atmosphere of dry hydrogen at $1030^{\circ} \mathrm{C}$. 
The maximum density value obtained by the classical method reached $93 \%$ of the theoretical density. The second method was the HIP (hot isostatic pressing). Conditions of process were: pressure of $30 \mathrm{MPa}$, the temperature $1000^{\circ} \mathrm{C}$, time $30 \mathrm{~min}$, in an argon atmosphere. The densities obtained in this way reached the maximum $98 \%$ value of the theoretical density. The third method was the SPS (spark plasma sintering). The material was sintered under the following conditions: pressure of $50 \mathrm{MPa}$, a vacuum of $10^{-4} \mathrm{hPa}$, the temperature of $950^{\circ} \mathrm{C}$, time $15 \mathrm{~min}$. Density of $\mathrm{Cu} / \mathrm{G}$ composite were at $99.8 \%$ of the theoretical density. Composites of $\mathrm{Cu} / \mathrm{G}(\mathrm{CVD})$ moved up to a higher $-100 \%$ - position of pure copper density. Clear is, that from a material density point of view the SPS method is the best. Thermal properties were measured within the temperature range $50-600^{\circ} \mathrm{C}$ using the Laser Flash Analyser LFA457/Netzsch. The values of the specific heat for composite materials were determined from the rule of mixture.

\section{Results and discussion}

This paper presents the results of experimental studies concerning the copper and reinforcing phases in the various carbon nanoforms. The core of the research has been focused on thermal conductivity of these composites types. On the basis of analysis of the results, it was stated that diffusivity decreases drastically for the shares by volume of more than $0.1 \%$ MWNT. One of the reasons is the porosity of composites. At low concentration, the nanotubes are singly and porosity has not been observed in the area of the CNT connection with the $\mathrm{Cu}$ matrix. For MWNTs concentration above $0.1 \% \mathrm{MWNT}$ in the powder and in the structure of the sintered composite bundles of nanotubes were observed. Around the bundles the well-formed pores were visible (Fig. 4). The best results of the thermal conductivity in particular groups of the reinforcing carbon phase are shown in Fig. 5. Good result of composite thermal conductivity with graphene obtained from CVD, might be expected for two reasons. The first had arisen from theses cited in publications, about role of high quality structures of graphene obtained by CVD. The second was arising from the conditions of the CVD process. Copper powder before covering by the graphene layer was deoxygenated under a hydrogen atmosphere. The layers of graphene protected the copper against re-oxidation in contact with the ambient atmosphere. Therefore, it was easier to obtain by SPS the composite with density equal to theoretical density of copper.

A spectacular, consistent with previously published results, is a high thermal conductivity composites GNP(MWNT)/Cu only at small concentration of graphene form in the copper. Undoubtedly, as has been proved, this fact is associated with low porosity of such composites. Probably, the major problem is in native copper oxides and oxygen introduced into the composite by the graphene forms - more $\mathrm{G}$ then more oxygen in composite and disturbing of the interface $\mathrm{Cu}-\mathrm{G}$. It can be assumed that described MWNT selection procedure gave more homogeneous material than in GNP cases or the reason lies in the differences in quality or geometry of both graphene forms.

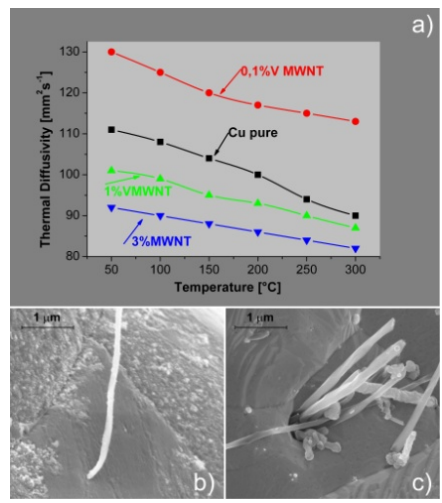

A)

Fig. 4. The results of: $\mathrm{A}-$ the thermal diffusivity for $\mathrm{Cu} / \mathrm{MWNT}$ materials (a), single MWNT in $\mathrm{Cu}$ grain (b) and the bundle of nanotubes inside the pore (c) and B - results of the thermal conductivity for GNP/ $\mathrm{Cu}$ composites obtained by HIP and SPS method (a) and SEM images of composites $(b, c)$

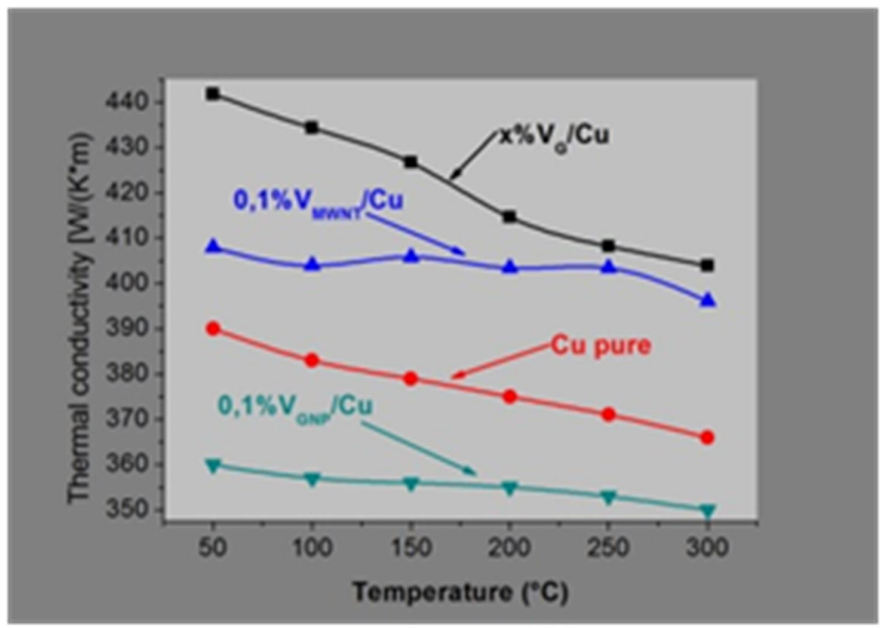

Fig. 5. The results of thermal conductivity composites materials, obtained during experiments

\section{Conclusion}

In this paper three type of copper-graphene composites materials are developed and presented. On the base of the obtained results we can state that:

i) The $\mathrm{Cu} / \mathrm{GNP}(\mathrm{MWNT})$ composites sintered by spark plasma sintering method are characterized by density close to theoretical,

ii) The thermal conductivity of $\mathrm{Cu} / \mathrm{GNP}(\mathrm{MWNT})$ composites is decreased with increasing GNP(MWNT) phases,

iii) Good thermal conductivity of composites is obtained using only a small GNP(MWNT) volume fraction,

iv) The best results of the thermal conductivity, greater than for pure copper, has been obtained for graphene coated $\mathrm{Cu}$ powder by using CVD technique. 
1310

\section{Acknowledgement}

The results presented in this paper were obtained as part of the „GRAMCOM" project (Contract No. GRAFTECH/NCBR/10/29/2013 with the National Centre for Research and Development) within the framework of the GRAF-TECH program and by the National Science Centre within a project „The correlation between interphase morphology and heat transfer in $\mathrm{Cu}-\mathrm{SiC}$ composites in function of the form of reinforcement material" awarded by decision number DEC-2014/13/B/ST8/04320.

\section{REFERENCES}

[1] F. Bonaccorso, A. Lombardo, H. Tawfique, S. Zhipei, L. Colombo, A.C. Ferrari, Materials Today 15 (12), 564-589 (2012).

[2] K. Pietrzak, N. Sobczak, M. Chmielewski, M. Homa, A. Gazda, R. Zybala, A. Strojny-Nedza, J. Mater. Eng. Perform. 25 (8), 3077-3083 (2016). DOI: 10.1007/s11665-015-1851-0.
[3] K.S. Novoselov, A.K. Geim, S.V. Morozov, D. Jiang, Nature 438 (7065), 197-200 (2005).

[4] T. Wejrzanowski, M. Grybczuk, M. Chmielewski, K. Pietrzak, K.J. Kurzydlowski, A. Strojny-Nedza, Mater. Design 99, 163-173 (2016).

[5] J.H. Lehman, M. Terrones, E. Mansfield, Carbon 49, 2581-2602 (2011).

[6] E. Pop, A. Varshney, K. Roy, MRS Bull. 37, 1273 (2012).

[7] Scientific Background on the Nobel Prize in Physics 2010, Graphene, compiled by the Class for Physics of the Royal Swedish Academy of Sciences, 5 October 2010.

[8] L. Hasselma, F. Johnson, J. Compos. Mater. 21, 508-515 (1987).

[9] K. Jagannadham, J. Vac. Sci. Technol. B 30, 039-109 (2012).

[10] F. Chen, J. Ying, Y. Wang, Carbon 96, 836-842 (2016).

[11] J. Seo, W.S. Chang, T. Kima, Thin Solid Films 584, 170-175 (2015).

[12] M. Park, B.H. Kim, S. Kim, Carbon 49, 811-818 (2011). 